\title{
Study on Current Status, Problems and Countermeasures of Countryside Health and Wellness Tourism in China
}

\author{
Chunya Feng', Huanyong $\mathrm{Li}^{2}$, Li Feng 3 , Mingli Yu², Hongxia Zhang', Yiwei Ma², Yanfang Yao5, \\ Shengai Zhang ${ }^{2 *}$, Zhuqi Zhang \\ ${ }^{1}$ Changchun Polytechnic, Changchun, China \\ ${ }^{2}$ Binzhou Vocational College, Binzhou, China \\ ${ }^{3}$ Shuangyashan Agricultural Broadcasting and Television School, Shuangyashan, China \\ ${ }^{4}$ Bincheng District Agricultural and Rural Bureau, Binzhou, China \\ ${ }^{5}$ Binzhou Public Utilities Service Center, Binzhou, China \\ Email: ^3217080070@qq.com, *1075626477@qq.com
}

How to cite this paper: Feng, C. Y., Li, H. Y., Feng, L., Yu, M. L., Zhang, H. X., Ma, Y. W., Yao, Y. F., Zhang, S. G., \& Zhang, Z. Q. (2021). Study on Current Status, Problems and Countermeasures of Countryside Health and Wellness Tourism in China. Open Journal of Social Sciences, 9, 212-221.

https://doi.org/10.4236/jss.2021.94016

Received: March 11, 2021

Accepted: April 19, 2021

Published: April 22, 2021

Copyright $\odot 2021$ by author(s) and Scientific Research Publishing Inc. This work is licensed under the Creative Commons Attribution International License (CC BY 4.0).

http://creativecommons.org/licenses/by/4.0/

\begin{abstract}
This paper introduced the concept and origin of countryside health and wellness tourism, expounded the current status and development trend of countryside health and wellness tourism in China, discussed and analyzed the problems existing in the development process of countryside health and wellness tourism in China, and put forward the countermeasures and suggestions for the development of countryside health and wellness tourism. It is the mission of modern tourism researchers to explore the essence of regional culture for serving today's health and wellness tourism.
\end{abstract}

\section{Keywords}

Countermeasure, Countryside, Current Status, Health and Wellness, Problem, Suggestion, Tourism

\section{Introduction}

The countryside health and wellness tourism refers to a series of leisure and health-keeping activities (e.g. recreation, vacation, recuperation, health care etc.) and other entertainment and health activities carried out by people in rural areas relying on clean and beautiful natural environments and lively folk customs with good ecological landscape, so as to enjoy the happiness, comfort and beauty brought by the fresh air, clean water, good food and relaxed pace of life in rural ${ }^{\star}$ Corresponding author: Shengai Zhang; Co-corresponding author: Hongxia Zhang. 
areas (Tharakan, 2013; Yang Zhenzhi, 2016). This is a new form of tourism developed in recent years in china.

With the development of society and the progress of science and technology, the pace of people's work and life is speeding up, and the pressure in their hearts is increasing. So, the fast-paced lifestyles and heavy-pressure works seriously affect people's health. According to the White Paper on the Health Status of White-Collar Workers in China's Cities, the proportion of sub-health whitecollar in major cities of China reached $76 \%$ in 2017 , of which nearly $60 \%$ was in the status of overwork, and less than 3\% was truly healthy (Henderson, Joan C., 2003; Chen Chun, 2019). In addition, the problems of obesity and overweight are very serious in Chinese residents. According to the Report on Nutrition and Chronic Diseases of Chinese Residents released by the National Health and Family Planning Commission in 2015, the overweight rate of adults aged 18 and above in China was $30.1 \%$, and the obesity rate was $11.9 \%$. The growth rate of overweight and obesity was higher than that of developed countries. This shows that chronic diseases and obesity have seriously affected the health status of Chinese residents (Zhu Guifeng, 2010). And countryside health and wellness tourism activities, can make people go into the nature, feel the pastoral scenery and natural beauty, which not only can get exercises and self-cultivation, improve the level of physical health, but also can effectively adjust people's psychological pressure and physical health status, reduce people's mental pressure, and effectively improve people's health level (Pramod Bubna, 2013).

\section{Current Status and Development Trends}

Health and wellness tourism in foreign originated in the early 14th century. The emergence of hot spring resort was the embryonic form of modern health tourism (Goodrich \& Goodrich, 1987). At the end of the 20th century, wellness tourism emerged in North America, and the medical treatments and the nursing were added in the health tourism (Henderson, Joan C., 2003; Han Xiao, 2011). In 1977, the International Tourism Organization published "Development details in tourism" and "Comprehensive plan in tourism", which were the most representative works on health and wellness tourism abroad (Zhu Guifeng, 2010; Qin Xiuhong, 2014). Professor Edward Inskeep, an American Tourism Planner, had made an in-depth study on health and wellness tourism. He had published the famous "National regional tourism planning opinions", and put forward the basic concept of regional health and wellness tourism, which provided a theoretical basis for the later research on the development planning of health and wellness tourism industry (Yin Shijie, 1999; Smith \& Kelly, 2006; Smith Melanie \& Puczko Laszlo, 2009). In recent years, the model of health and wellness tourism has been applied by many countries in tourism industry. The relevant departments of Australia have formulated the Health and Wellness Tourism Plan, which is conducive to the stable and rapid development of the health and wellness tourism industry in the region (Bennet et al., 2004). The famous scholars in 
Mexican have made a in-depth research on the strategic measures of health and wellness tourism, and carried out practice and application, and achieved good results. The health and wellness tourism in China is a new form of tourism emerged from the modern tourism industry, which has been highly concerned since its birth. As a special tourism, the health and wellness tourism relates to every tourist's pursue of life. Therefore, the health and wellness tourism in China differs a lot from 'medical tourism' or 'health care tourism', which is translated by the western some countries, and it owns distinct characters (Schobersberger, W., 2000). At present, China's health and wellness tourism is mainly concentrated in forest parks, health-spa, characteristic food, rural scenery and ancient villages and towns and so on, and experience, sightseeing, leisure and accommodation are the main forms of tourism products currently developed. The development level of tourism products is relatively low, and a complete countryside health and wellness tourism system has not been formed. At the same time, the industry chain of countryside health and wellness tourism is relatively weak, the extension of products and services is not enough, and wellness and medical care and other special services need to be further strengthened (Guo Huancheng et al., 2008; Yin Shijie, 1999). In recent years, many basic theoretical topics of health and wellness tourism such as the connotation, development model and operation mechanism have been studied in China. Some scholars believed that health and wellness tourism was a kind of integration of health tourism and health-cultivation tourism, which was a tourism form of nursing one's body by sightseeing, health care and entertainment based on the natural ecology and cultural environment to achieve the purpose of self-cultivation, health care and rehabilitation. Yang Zhenzhi analyzed the emergence, concept, connotation and philosophical basis of health and wellness tourism in "Written talk on China's tourism development". He pointed out that the aging of population had increased the development space of health and wellness tourism market, and revealed the new trend of tourism development (Yang Zhenzhi, 2016).

\section{Main Problems and Analysis}

1) The design and project development of countryside health and wellness tourism area are simple and random, and lack of scientific and reasonable longterm planning.

In the management model and development project of countryside health and wellness tourism, people lacked of advanced design concept, and ignored the in-depth excavation of farming culture, local folk culture and minority culture. There was a tendency that only focuses on scale, not on quality; only look at the current situation, not regard the long-term in the process of development (Ladkin \& Bertramini, 2002). At present, most countryside health and wellness tourism projects are small-scale tourism projects established by farmers themselves relying on rural natural resources such as farmland, orchard, mountain forest and pond etc. These projects are simple and random, have no long-term plan and 
lacks scientific overall tourism planning. Just as people vividly summed up: "a few houses, a few tables, climbing mountains, drinking tea, playing mahjong, fishing and catching shrimp" (Tian Guangzeng, 2007; Li Hong, 2019). Although this kind of evaluation has exaggerated elements to a certain extent, it also indeed tells us the current status of rural tourism development in China. Without a long-term development plan, tourism projects will be traditional and single, which will lead to small scale, insufficient connotation, low level and no distinctive local characteristics, at the same time, this also will lead to the disordered development of tourism projects, the repeated construction of facilities and the serious waste of resources and manpower.

2) The resources of countryside health and wellness tourism lack in-depth development, and the connotation of which needs to be expanded.

The development of countryside health and wellness tourism resources is different from the development of other tourism resources, which needs to show more local culture. At present, the development projects of countryside health and wellness tourism in China are still in an exploratory stage, development contents are very monotonous, and lack in-depth development. The many projects of countryside health and wellness tourism areas mainly focus on agricultural sightseeing and local products tasting, which do not really reflect the deep connotations of countryside health and wellness tourism (Lomine \& Edmunds, 2007; Li Hong, 2019). After the rapid development in recent years, the development of countryside health and wellness tourism in China has achieved initial results. The hardware can basically meet the needs of most consumers, but there is still a certain gap in software, especially, the local native culture and the cultural products represented by rural folk customs all need to be deepened further (Zhang Ning, 2019). In other words, the current projects and products of countryside health and wellness tourism only have met people's low-level material needs, but not met people's high-level spiritual needs. In addition, at present, in the development of countryside health and wellness tourism, people only pay attention to the connotation of sightseeing and leisure, but do not to the connotation of health and wellness. Health care, nursing, medicine, especially traditional Chinese medicine has still not been included into the connotation of countryside health and wellness tourism. The main reason is that there is no accurate positioning in the process of countryside health and wellness tourism development, which also is an important factor to lead the lack of health and wellness connotation in development projects.

3) Consumer's lack in-depth understanding on the connotation of countryside health and wellness tourism, and the consumption concept is not mature enough.

At present, countryside health and wellness tourism stays at a lower level, only emphasizes material enjoyment, but does not pay enough attention to the role of spiritual level. Consumers only position countryside health and wellness tourism on the level of enjoying rural scenery, and basically do not participate in the re- 
cuperative and experiential entertainment activities provided by the tourism area. They only pay attention to material enjoyment, and have a special preference for local products and local dishes, but they are not interested in health care. Only a small number of consumers with high education level and good economic conditions choose to go to rural tourism and vacation without consideration of cost, they need to obtain spiritual enjoyment in a clean, natural and beautiful environments in the process of rural tourism, not just material enjoyment (Tian Guangzeng, 2007). In addition, some consumers have the psychology of "joining in the fun", they only go to travel in the peak season, while rarely go in the off-season, which will form a low and peak season of tourism, and lead to the waste of infrastructure and the decline of service quality.

4) The model of operation is single and it lacks distinctive features.

Although the countryside health and wellness tourism in China has shown a bright future, the model of operation of countryside health and wellness tourism is relatively simple, the in-depth excavation of farming culture, local folk culture and minority culture has been ignored, and it has not formed distinctive characteristics. Many countryside health and wellness tourism enterprises mainly focused on rural entertainments (e.g. eating farm meals, living in rural houses, doing farm work, etc.), seasonal fruit and vegetable picking, fishing and other leisure entertainment activities, but did not fully tap the farming culture and local folk customs in countryside. Therefore, it is difficult to meet the needs of multilevel, diversified and high-grade tourism. Many tourists have been there only once, and have no desire to go again (Wang Guizhong, 2002; Guo Huancheng et al., 2008). In addition, many rural tourism enterprises ignored the development of characteristic agricultural products, the products sold were similar, and it was difficult to attract tourists. In the process of urbanization, the unique resources with local flavor in some villages have been disappearing, especially, some natural and semi natural ecological environments and landscapes have been destroyed, which makes the development of rural health tourism project lose its own advantages, and cannot form its own characteristic brands.

\section{Countermeasures and Suggestions}

The countryside health and wellness tourism in China is still in the initial stage of development, people's understanding on the connotation countryside health and wellness tourism is not comprehensive enough, and there are still some problems to be solved in the development process. If these problems cannot be solved in time and effectively, the development of countryside health and wellness tourism will be restricted, the rural economic development and the process of new rural construction also will be affected. In order to promote the healthy development of countryside health and wellness tourism, we have made in-depth and detailed investigation and research, and put forward the following specific and effective countermeasures and suggestions.

1) Making a long-term overall plan to avoid blind development. 
In the process of making the planning of countryside health and wellness tourism, we must coordinate the overall planning, regional tourism and the overall planning of the development of the surrounding cities to adapt to the regional tourism planning and urban development planning. In the process of overall planning, the structural advantages of local rural tourism resources, the specific regional scope of development, tourism projects and related supporting projects should be listed in detail. In the construction of landscape architecture and tourism facilities, we should pay attention to their coordination with the surrounding environments, and strive to achieve the perfect unity between the natural environments and the artificial environments. This requires three basic states to be maintained in the process of countryside health and wellness tourism development: namely, the ecological landscape facilities, the original building materials and the original ecological foods. In the process of landscape construction, we should protect the original natural scenery and environments according to the characteristics of rural natural resources, especially pay attention to the protection of forest and vegetation. The natural waterscape and original ecological wetland system in the rural areas should be fully protected, and then a harmonious and natural water system landscape should be created around them. In a word, in the process of construction, we should strive to create the original landscape of rural areas, not the landscape of urbanization. At the same time, we should also consider the need of sustainable development, and put an end to the short-term behavior of "only focusing on the immediate and ignoring the longterm".

2) Strengthening the understanding of tourism purpose in the new era and enriching the connotation of health and wellness tourism.

With the development of society and the improvement of living standards, the main purpose of tourism is no longer to exercise simply. In the process of tourism, people pay more and more attention to the improvement of their comprehensive quality and the needs of health preservation. In order to give full play to the potential and advantages of tourism industry, it is necessary to fully understand the connotation of countryside health and wellness tourism, deeply explore the new development model of countryside health and wellness tourism (Mueller \& Kaufmann, 2001). Only in this way, can we improve further the quality and efficiency of tourism industry. Therefore, according to the rural location and the actual conditions of rural tourism, we should use scientific research methods to comprehensively analyze the development of rural tourism. We should introduce the new concept of countryside health and wellness tourism into the existing rural tourism industry to develop the new rural tourism industry, which will play a positive role in promoting the upgrading of China's tourism industry, the development of rural economy and new rural construction.

3) Reforming the traditional tourism model and innovating the development model of countryside health and wellness tourism.

At present, the development models of countryside health and wellness tour- 
ism in China mainly include: the rural sightseeing tourism model with unique natural scenery (e.g. big lakes, big rivers, big plains, big wetlands, big forests, etc.) as the main contents, the rural cultural tourism model with folk culture, farming culture and ethnic minority culture as the main contents, the rural experiential tourism model with the leisure and sports activities (e.g. skiing, rafting, fishing, hot spring, etc.) as the main contents, the "happy farm " tourism model with eating farm meals, living in farmhouses, doing farm works as the main contents, and the rural agricultural tourism model of modern agricultural sightseeing garden and vegetable and fruit picking garden as the main contents. These tourism models all regarded "sightseeing, appreciation and entertainment" as the main contents, but the connotation of "health and wellness" was ignored. Therefore, China's countryside health and wellness tourism should pay attention to the connotation of health and health preservation in the next step of development, health care, nursing and medicine, especially traditional Chinese medicine should be embedded in the contents of rural health tourism, so as to innovate the development model of countryside health and wellness tourism.

4) Excavating the rural traditional culture and highlighting the characteristics of folk customs.

In the development of countryside health and wellness projects, we should deeply explore the local traditional culture, highlight the characteristics of folk customs, so that consumers can feel the cultural background of the local countryside, and respect the local folk customs more, at the same time, this also makes the local residents have more self-esteem, self-love and self-confidence. Through the development of these tourism projects, the local residents can realize the intrinsic value of their own culture, and increase the mutual respect for the local culture in the whole society. In addition, in the process of tourism project development, we should fully reflect the inherent cultural connotation of rural tourism resources according to the characteristics of rural culture, and maintain the distinctive characteristics of rural cultural resources. Only in this way, the local flavor and atmosphere of rural traditional culture can be increased, the cultural content of rural tourism and the participating enthusiasm of tourists also can be increased, which can effectively extend the stay time of tourists, enhance the effectiveness and practicability of tourism projects, and gradually form excellent projects. In the process of tourism development, tourism projects with different demands should be developed according to different consumption needs, so as to increase the number of tourists, expand the market share, and promote the development of rural regional economy.

5) Protecting the local natural ecological environments and taking the road of sustainable development.

In the development of countryside health and wellness tourism, some places only pay attention to the development and utilization of natural resources, but ignore the protection of natural resources and ecological environments, which make countryside health and wellness tourism industry lose the after momentum of the development (Harrison et al., 2003). In the future, in the process of 
developing countryside health and wellness tourism, we should adhere to the principle of sustainable development, and take into account economic benefits and environmental issues while striving to develop tourism. Once the ecological environments in rural areas are destroyed, it is difficult to manage them. If we only pursue economic benefits, and neglect environmental protection, the tourism industry will be abandoned halfway. Therefore, in the process of countryside health and wellness tourism development, we should attach great importance to the protection and improvement of ecological environments. First, the government should actively guide tourism enterprises to consider the value of natural ecological resources, seriously grasp the bearing capacity of nature and society, and avoid that the ecological environments are damaged through controlling the number of tourists, limiting the time of tourism, and limiting the use of highly polluting vehicles. Second, the government should strengthen the supervision to rural environmental problems, regularly carry out environmental inspection to various rural tourism areas, and urge tourism enterprises to solve the environmental deterioration problems that may be brought about by tourism activities. Third, tourism enterprises themselves should actively guide tourists to improve the consciousness of protecting tourism environments.

\section{Concluding Remarks}

Countryside health and wellness tourism is an urgent need for people to live healthily and release pressure, which has existed since ancient times. With the development of society and the progress of science and technology, the pace of people's work and life is speeding up, and the pressure is also increasing, but the bearing capacity of people's heart is declining. While countryside health and wellness tourism can help people to enter the nature and feel the rural scenery and natural beauty, which can not only exercise, cultivate people's physical fitness, improve their health level, but also effectively regulate people's psychological pressure and physical health status, reduce people's life pressure, and effectively improve people's health level. In the future, we should further expand the connotation of countryside health and wellness tourism, and bring the healthpreservation, nursing, medicine, especially traditional Chinese medicine into it, so as to develop countryside health and wellness tourism to "pastoral health and wellness complex" model.

\section{Acknowledgements}

This study was supported by the key research project of Binzhou Social Science Planning in 2020 (Project No. 20-SKGH-79), the Modern Agronomic Skill Master studio of Binzhou and Circular Agriculture Master Studio of Binzhou Vocational College.

\section{Conflicts of Interest}

The authors declare no conflicts of interest regarding the publication of this paper. 


\section{References}

Bennet, M., King, B., \& Milner, L. (2004). The Health Resort Sector in Australia: A Positioning Study. Journal of Vacation Marketing, 10, 122-137. https://doi.org/10.1177/135676670401000203

Chen, C. (2019). Research Summary of Health and Wellness Tourism at Home and Abroad. Journal of Panzhihua University, 36, 43-47.

Goodrich, J. N., \& Goodrich, G. E. (1987). Health Care Tourism-An Explanatory Study. Tourism Management, 8, 217-222. https://doi.org/10.1016/0261-5177(87)90053-7

Guo, H. C., Sun, Y., Ren, G., \& Lv, M. (2008). Study on the Development of Leisure Agriculture and Rural Tourism in Beijing. Geo-Information Science, 10, 453-461.

Han, X. (2011). Comparison of the Developmental Patterns of Rural Tourism International and Domestic. Reformation \& Strategy, 27, 184-186.

Harrison, L. C., Jayawardena, C., \& Clayton, A. (2003). Sustainable Tourism Development in the Caribbean: Practical Challenges. International Journal of Contemporary Hospitality Management, 15, 294-298. https://doi.org/10.1108/09596110310482227

Henderson, J. C. (2003). Healthcare Tourism in Southeast Asia. Tourism Review International, 7, 111-121. https://doi.org/10.3727/1544272031437692

Ladkin, A., \& Bertramini, A. M. (2002). Collaborative Tourism Planning: A Case Study of Cusco, Peru. Current Issues in Tourism, 5, 71-93.

https://doi.org/10.1080/13683500208667909

Li, H. (2019). Review and Prospect of Health Tourism Research. Business Economics, No. $4,50-52$.

Lomine, L., \& Edmunds, J. (2007). Key Concepts in Tourism. New York, NY: Palgrave Macmillan.

Mueller, H., \& Kaufmann, L. E. (2001). Wellness Tourism: Market Analysis of Special Health Tourism Segment and Implications for the Hotel Industry. Journal of Vacation Marketing, 7, 5-17. https://doi.org/10.1177/135676670100700101

Pramod, B. (2013). Multiplier Effect in Medical Tourism: A Case Study Reference to Rajasthan. Asia Pacific Journal of Marketing \& Management Review, 2, 100-111.

Qin, X. H. (2014). Research on Development Strategy of Healthcare Tourism Situation in Thailand. Around Southeast Asia, No. 11, 57-61.

Schobersberger, W. (2000). Alpine Health Tourism: Future Prospects from a Medical Perspective (pp. 340-346). HIS-Institute Humpeler Schobersbersberger Leisure Futures 2002, Innsbruck: University of Innsbruck.

Smith, M., \& Kelly, C. (2006). Wellness Tourism. Tourism Recreation Research, 31, 1-4. https://doi.org/10.1080/02508281.2006.11081241

Smith, M., \& Puczko, L. (2009). Health and Wellness Tourism. Waltham, MA: ButterworthHeinemann Publications.

Tharakan, Y. G. (2013). A Model for Sustainable Health and Wellness Tourism at Manipal Based on Hypothetical and Motivational Analysis. 4th International Research Symposium in Services Management, Kerala, 2-6th July 2013, 25-26.

http://eprints.manipal.edu/id/eprint/137534

Tian, G. Z. (2007). Medical Service Travel Development Research of Our Country. Journal of Anyang Teachers College, No. 5, 93-96.

Wang, G. Z. (2002). Study on Actuality and Developmental Strategy of Physical Educatyon Tourism in Our Country. Sports Science Research, 23, 53-55.

Yang, Z. Z. (2016). Written Talk on China's Tourism Development Tourism and Health 
Wellness. Tourism Tribune, 31, 1-4.

Yin, S. J. (1999). Development Trend of China's Tourism Consumption. Seeker, No. 6, 4-7.

Zhang, N. (2019). Study on the Development of Rural Health Tourism in Tangshan under the Strategy of Rural Revitalization. Chinese and Foreign Entrepreneurs, No. 7, 154-155.

Zhu, G. F. (2010). Research on Rural Tourism Development in Heilongjiang Province under the Background of New Rural Construction. Journal of Changchun Normal University (Natural Science), 29, 66-68. 